\title{
Formação continuada de professores do Ensino Fundamental: percepçōes a respeito da pesquisa científica e sua contribuição para auxiliar na Feira do Conhecimento
}

Caroline Medeiros Martins de Almeida*, Camila Maria Bandeira Scheunemann**, Letícia Azambuja Lopes ${ }^{\star \star *}$, Paulo Tadeu Campos Lopes ${ }^{\star \star \star *}$

\section{Resumo}

O objetivo desse estudo foi analisar as percepções de professores do Ensino Fundamental sobre pesquisa científica, suas dificuldades de implementação nesse nível de ensino e qual a contribuição da formação realizada para a orientação da pesquisa científica para a Feira do Conhecimento. Trata-se de um estudo de caso com natureza qualitativa, envolvendo 81 professores dos anos iniciais e finais do Ensino Fundamental de 24 escolas de uma rede municipal da região metropolitana de Porto Alegre, RS. Foi aplicado um questionário sobre o perfil profissional, conhecimentos sobre pesquisa científica e as percepções dos professores sobre a formação, que foi analisado com base na Análise de Conteúdo. Os resultados revelaram que os professores consideram importante trabalhar a pesquisa científica com os alunos, e apontaram como dificuldades mais impactantes na implementação da pesquisa científica no Ensino Fundamental aspectos como a falta de tempo para desenvolvê-la na escola e a falta de recursos para esta finalidade. Atribuíram a formação como válida por melhorar o entendimento sobre o assunto, garantir suporte e orientação para a aplicação da pesquisa científica em sala de aula e auxiliar na construção de trabalhos para a Feira do Conhecimento.

Palavras-chave: Pesquisa científica. Formação docente. Ensino Fundamental. Feira do conhecimento.

\footnotetext{
Professora do Programa de Pós-graduação em Gestão Educacional da Universidade do Vale do Rio dos Sinos, Brasil. E-mail: carolinemalmeida@unisinos.br

* Doutoranda do Programa de Pós-Graduação em Ensino de Ciências e Matemática da Universidade Luterana do Brasil, Brasil. E-mail: camila.b91@hotmail.com

*** Professora do Programa de Pós-Graduação em Ensino de Ciências e Matemática da Universidade Luterana do Brasil, Brasil. E-mail: leazambuja@gmail.com

*.** Professor do Programa de Pós-Graduação em Ensino de Ciências e Matemática da Universidade Luterana do Brasil, Brasil. E-mail: pclopes@ulbra.br
}

Recebido em: 27/04/2020 - Aceito em: 05/12/2020

https://doi.org/10.5335/rbecm.v4i1.10902

http://creativecommons.org/licenses/by-nc-nd/4.0 


\section{Introdução}

A metodologia que o professor do Ensino Fundamental utiliza para ensinar a pesquisa científica é baseada na sua formação inicial acadêmica, a qual nem sempre é suficiente para suprir toda a necessidade de conhecimentos e aportes para auxiliá-los nesse processo. Galiazzi e Moraes (2002), em favor de educar pela pesquisa, argumentam como elemento central a ideia de que a qualidade da formação inicial dos professores pode ser melhorada com a integração da pesquisa neste processo. Os autores comentam que repensar e reestruturar a formação de professores com bases na pesquisa pode atingir a melhoria de sua qualidade, superando a aula caracterizada pela simples cópia. Crisostimo et al. (2018) relatam que a formação de professores é um meio para superar um ensino limitado e tradicional, sem a participação ativa dos envolvidos no processo de ensino e aprendizagem, sendo um dos seus desafios promover o diálogo, a investigação, a pesquisa e o contato com diferentes ambientes de aprendizagem.

Bedin e Del Pino (2019) destacam que seguindo as ideias das Diretrizes Curriculares Nacionais (BRASIL, 2002) para a formação docente, o professor que sai da universidade precisa estar empenhado com o ensino básico de forma qualificada e apresentar habilidades para se expressar de maneira clara e objetiva, desenvolvendo metodologias diferenciadas para facilitar o processo de ensino e aprendizagem e colocar o estudante como agente ativo desse processo. Assim, um professor empenhado é aquele engajado, que se sente responsável pela sua profissão, que atua diretamente nas necessidades da escola, dos alunos e dos processos de ensino e aprendizagem contemporâneos.

A pesquisa como princípio científico e educativo faz parte de todo processo emancipatório, no qual se constrói um sujeito autossuficiente crítico, autocrítico e participante (DEMO, 2011). Assim, trabalhar com a pesquisa científica desafia os jovens a pensar e fazer ciência, proporcionando uma aproximação à área que o aluno possui maior interesse, enfatizando a melhoria de sua análise crítica e capacidade de resolver problemas (FAVA-DE-MORAES; FAVA, 2000; BIANCHETTI et al., 2012).

Referenciando a pesquisa científica na Educação Básica, Pedro Demo comenta:

É possível desenhar o alcance alternativo da pesquisa, que a tome como base não apenas das lides científicas, mas também do processo de formação educativa, o que permitiria introduzir a pesquisa já na escola básica, a partir do pré-escolar e considerar atividade humana processual pela vida afora (DEMO, 2011, p. 9). 
Desta forma, para Demo (2011), a pesquisa deve aparecer em todo projeto educativo, na base de qualquer proposta emancipatória, pois se educar é sobretudo motivar a criatividade do aluno para que surja o novo mestre e não o discípulo, a atitude de pesquisa é parte intrínseca. Silva e Moura (2019) explicam que as feiras científicas são eventos realizados em escolas ou na comunidade como uma das formas de promover a pesquisa, com o objetivo de proporcionar um diálogo com os visitantes e uma discussão sobre os conhecimentos, os quais os alunos são responsáveis pela apresentação de projetos planejados e executados por eles, e auxiliados pelos professores.

Tendo em vista a importância de inserir a pesquisa científica no Ensino Fundamental e auxiliar os professores neste processo, foi promovida uma formação para docentes deste nível de ensino sobre a pesquisa científica e Feiras do Conhecimento. Diante do exposto, buscou-se responder a pergunta: Quais as percepções dos professores de Ensino Fundamental sobre a pesquisa científica, suas dificuldades de implementação neste nível de ensino e qual a contribuição da formação realizada para a orientação da pesquisa científica para a Feira do Conhecimento?

Assim, o objetivo foi analisar as percepções de professores do Ensino Fundamental sobre pesquisa científica, suas dificuldades de implementação nesse nível de ensino e qual a contribuição da formação realizada para a orientação da pesquisa científica para a Feira do Conhecimento.

\section{Referencial Teórico}

É importante que o professor incentive e cative o aluno pelo gosto da pesquisa desde a Educação Básica, pois ela tem uma função importante no desenvolvimento cognitivo do estudante, auxiliando-o na construção do conhecimento, na autonomia, na análise crítica-social e elevando a sua maturidade intelectual. Ovigli (2014) destaca que a pesquisa científica tem como objetivo incentivar a valorização da formação científica logo na Educação Básica, pois a iniciação à pesquisa não é importante apenas porque exercita os instrumentos de construção de conhecimentos, mas também porque é considerada uma importante estratégia para os professores e estudantes interferirem e reconstruírem a realidade observada.

Segundo Mattos et al. (2016) a pesquisa na Educação Básica ainda é recente, com pouca divulgação e desenvolvimento nas escolas, porém sua prática é necessária porque 
traz propostas que colocam os estudantes como pesquisadores em processo de iniciação, promovendo o desenvolvimento do raciocínio científico, da criatividade e da autonomia. Demo (2011, p. 9) fala da importância da pesquisa e relata que "a ideia é fundamentar proposta de teoria e prática da pesquisa que ultrapasse os muros da academia e da sofisticação instrumental”.

Chassot (2000) define que ciência pode ser considerada como uma linguagem construída para explicar o mundo natural. O conhecimento científico contribui para que o aluno desenvolva seu senso investigativo e o instigue, auxiliando no ensino e aprendizagem, pois a pesquisa minimiza a prevalência do ensino tradicional e oportuniza a formação de um aluno mais crítico e reflexivo (SOUZA; CEDRO; MORBECK, 2019).

A Base Nacional Comum Curricular (BNCC) apresenta a concepção de que os estudantes não são tábua rasa, mas possuem vivências, saberes, interesses e curiosidades sobre o mundo natural e tecnológico que devem ser valorizados e mobilizados. Assim, inserir a investigação científica como passo inicial do processo de aprendizagem, aproximando os estudantes a situações de suas vivências, de forma integrada às diversas temáticas contemporâneas relacionadas à vida humana, se torna um processo que promove o letramento científico, onde estabelecer relações entre um conjunto complexo de elementos que permeiam a vida cotidiana e o ensino de Ciências a partir da investigação acerca das vivências dos estudantes, aproximando e dialogando com as diversas realidades e temáticas, é um dos meios de garantir direitos de aprendizagem (BRASIL, 2019).

É importante ressaltar que a BNCC, como documento norteador da Educação, traz a proposta do ensino por investigação aplicado ao processo de ensino e aprendizagem das Ciências da Natureza. Tendo como proposta básica o ensino por habilidades e competências e, especificamente para o ensino de ciências, traz uma abordagem que promove o letramento científico a partir do ensino por investigação, que envolve a capacidade de compreender e interpretar o mundo (natural, social e tecnológico), mas também de transformá-lo com base nos aportes teóricos e processuais das ciências (BRASIL, 2019).

Considerando os objetivos da BNCC (BRASIL, 2019) e os aspectos relacionados ao letramento científico no ensino de Ciências da Natureza, observa-se o importante papel da formação inicial de professores, tendo em vista que este será o primeiro contato dos futuros educadores com assuntos relacionados ao ensino de Ciências da Natureza, e as abordagens realizadas para que a aprendizagem ocorra dentro de um processo investigativo. 
Nesta perspectiva, Chassot (2003) explica que a alfabetização científica pode ser considerada uma das alternativas para potencializar a educação mais comprometida, e enfatiza que essa deve ser uma preocupação significativa no Ensino Fundamental, necessitando de atenções quase idênticas às do Ensino Médio. $\mathrm{O}$ autor ainda destaca que:

Hoje não se pode mais conceber propostas para um ensino de ciências sem incluir nos currículos componentes que estejam orientados na busca de aspectos sociais e pessoais dos estudantes. Há ainda os que resistem a isso, especialmente quando se ascende aos diferentes níveis de ensino. Todavia, há uma adesão cada vez maior às novas perspectivas (CHASSOT, 2003, p. 90).

Por isso, o professor do Ensino Fundamental precisa qualificar-se constantemente, aprimorando a sua prática docente, no que tange à pesquisa científica, facilitando o entendimento dos conhecimentos científicos para os alunos. Assim, a adoção de atividades investigativas são um importante recurso didático para incentivar o ensino por investigação, proposto por Sasseron (2019), e para a formação inicial e continuada de professores. É importante refletir sobre a formação de pessoas aptas para enfrentar as novas demandas do século XXI e, sobre a contribuição deste tipo de atividade para um ensino mais eficaz, de qualidade e que desperte o interesse dos jovens para as áreas de ciência e tecnologia (OVIGLI; COLOMBO JUNIOR; GALANTE, 2019).

Souza, Cedro e Morbeck (2019) ressaltam que as formações para o público docente sobre conhecimento científico não se apresentam acessíveis para todos os professores, além de despertar pouco interesse, em grande parte das vezes, o que dificulta a inserção da pesquisa científica em sala de aula, ainda pouco compreendida pelos alunos. Bedin e Del Pino (2019) discutem a formação de professores, a prática docente e o desenvolvimento do ensino com vistas à inserção da pesquisa em sala de aula, e reforçam que é recorrente e constante o desafio de ensinar e aprender por meio da pesquisa neste ambiente.

Para Mancuso (2000), as feiras científicas trazem benefícios tanto para os alunos quanto para os professores, pois revelam alternativas para mudanças no ensino, tais como: o crescimento pessoal, a ampliação dos conhecimentos e da capacidade comunicativa, mudanças de hábitos e atitudes, maior envolvimento e interesse e o desenvolvimento da criticidade. Farias (2006) pontua que as feiras científicas podem contribuir para a socialização e troca de experiências de conhecimentos com a comunidade, possibilitando uma ampliação da visão de mundo dos participantes, 
expositores e visitantes da feira, permitindo a divulgação dos resultados das pesquisas, troca de experiências entre os pares, como forma de validação do conhecimento.

As feiras consideram a tendência de potencializar a divulgação científica e viabilizar a o ensino por investigação na Educação Básica, proporcionando um enriquecimento curricular, oportunizando contextualização e interdisciplinaridade aos conteúdos trabalhados (OVIGLI; COLOMBO JUNIOR; GALANTE, 2019; SASSERON, 2019). O desenvolvimento científico e tecnológico e o processo de industrialização, intimamente vinculado ao progresso da Ciência, vem transformando e influenciando tanto o modo de vida das pessoas, quanto ao equilíbrio ambiental do planeta. Isso tem sido motivo suficiente para muitos educadores defenderem a necessidade de formar cidadãos capazes de compreender e usar as informações científicas para tomar decisões pessoais e socialmente responsáveis. Sem falar que esses conhecimentos e habilidades são, cada vez mais, cruciais para a inserção dos sujeitos no mercado de trabalho e na vida em sociedade (SCHWARTZMAN, 2015).

De acordo com Bogner, Boudalis e Sotiriou (2014) a aprendizagem baseada em investigação tem algumas características específicas: os alunos executam etapas de pesquisa semelhantes aos cientistas; sob orientação docente, os estudantes assumem o controle do processo de aprendizagem, construindo seus conhecimentos; a possibilidade de explorar problemas do mundo real; construção de conceitos e conhecimentos por meio de investigações; a aprendizagem ocorre de forma colaborativa; os alunos refletem sobre seu próprio processo de aprendizagem, se envolvem cognitivamente nas atividades de pesquisa; o aprendizado do aluno abrange competências independentes do domínio específico; esta abordagem entende que a aprendizagem não é memorização de fatos e sim compreensão do processo de descoberta.

Nesta perspectiva, há que se esperar que o ensino por investigação aumente o interesse em estudar Ciências, visto que, a autonomia dos discentes nas atividades os levam a uma maior motivação para lidar com os problemas científicos, também proporciona a criatividade e possibilita que os estudantes trabalhem com questões abertas. Pode propiciar, ainda, àqueles com maiores dificuldades, diversas maneiras de construção do conhecimento por meio da investigação, pois, a educação científica baseada em investigação leva em conta a diversidade dos alunos e suas particularidades na forma de aprender.

De acordo com estes pressupostos, é instigante que os professores do Ensino Fundamental também se apropriem da pesquisa científica, e despertem nos alunos o 
desejo e a curiosidade pela ciência, e que se amplie o entendimento de que pesquisa pode ser feita também por alunos da Educação Básica.

\section{Revisão de estudos empíricos}

Encontram-se na literatura alguns estudos que se empenharam em relatar práticas de iniciação à pesquisa científica na Educação Básica, por meio da participação em feiras científicas e eventos. Silveira, Cassiani e Linsingen (2018) realizaram um estudo com reflexões de um trabalho interdisciplinar, articulado em uma prática pedagógica de Iniciação Científica (IC) no 9º ano do Ensino Fundamental. Nesta pesquisa, os autores refletiram sobre outra possibilidade de relação entre escola, estudante, professor e o saber, numa identificação maior da escola com a formação científica emancipatória do aluno. Observaram que o exercício da pesquisa científica proporciona para o estudante um papel ativo e uma compreensão mais aprimorada e não ingênua dos fenômenos naturais, sociais e suas relações, fazendo com que não considere tão natural determinadas situações que envolvam sociedade, ciência e tecnologia.

Zompero et al. (2019) desenvolveram uma pesquisa sobre uma das formas de aproximar o aluno da aprendizagem de procedimentos científicos, que é a proposta da Iniciação Científica Júnior. O objetivo do estudo foi investigar a compreensão sobre procedimentos realizados em ciência de alunos participantes de um projeto de IC Júnior, e foi realizado com discentes do Ensino Médio de uma escola de Londrina, no Paraná. Os autores verificaram que a participação dos alunos no projeto favoreceu a aprendizagem de procedimentos em ciência, proporcionando conhecimentos mais consistentes sobre ciência e seus processos, o que auxilia na construção de competências propostas por documentos nacionais e internacionais de avaliação.

Outro estudo que relata experiência com IC Júnior é o de Thomé (2013), realizado no município de Curitibanos (SC) entre os anos de 2011 e 2012, o qual incentivou a iniciação à pesquisa científica com alunos de escolas básicas da rede pública estadual, visando um resgate histórico das instituições envolvidas, por meio de pesquisa historiográfica, com base em documentos escritos.

Rocha (2010) apresenta dados de um trabalho de introdução à pesquisa com alunos dos anos iniciais do Ensino Fundamental, realizado em 2008 no município de Uberlândia/MG. A temática abordada foi a reciclagem dos resíduos domésticos, 
as formas de reutilizá-lo e reciclá-lo, e entre as diversas atividades envolvidas estavam a observação dos espaços escolares, coleta de material reciclável, apresentação de peça teatral, trabalho de campo e confecção de brinquedos, culminando com a exposição do trabalho em um congresso.

Bernardes e Peixoto (2018) abordam a IC na Educação Básica e apresentam uma reflexão sobre sua inserção em escolas do Rio de Janeiro entre os anos de 2013 e 2017, e apontam a importância das universidades se aproximarem da escola, como apoio e suporte teórico para a inserção da pesquisa científica. O trabalho realizado consistiu em um projeto que incentiva os estudantes na criação de materiais para o ensino de Física, desenvolvendo uma postura ativa em suas aprendizagens, pois realizaram pesquisas, elaboração de textos, histórias, e fotonovelas no programa PowerPoint, apresentando para a comunidade o resultado por meio de uma mostra de fotonovelas.

Refletindo a respeito dos trabalhos encontrados referente a temática, observa-se que existem iniciativas buscando articular o ensino e a pesquisa na Educação Básica, intencionando aprimorar essa integração nas práticas pedagógicas, em prol de uma formação discente mais crítica e emancipatória. Tais exemplos, trazem indícios que auxiliam no repensar quanto à aproximação da pesquisa em âmbito educacional e como ela deve permear todo o processo educativo.

\section{Metodologia}

Trata-se de um estudo de caso, considerado por Yin (2015) como o delineamento mais adequado para a investigação de um fenômeno contemporâneo dentro do seu contexto real. A abordagem é qualitativa, pois tem a capacidade de representar as visões e perspectivas dos participantes de um estudo, podendo representar os significados dos fatos da vida real pelas pessoas que os vivenciam, não os valores, pressuposições, ou significados mantidos por pesquisadores (YIN, 2016).

A amostra consistiu em 81 professores dos anos iniciais e finais do Ensino Fundamental de 24 escolas de uma rede municipal da região metropolitana de Porto Alegre, Rio Grande do Sul - Brasil. Os referidos docentes foram convidados a participar da formação através da Secretaria de Educação do município, a qual seria a posterior promotora da Feira do Conhecimento; apesar disso, a participação na feira não estava condicionada à participação no curso de formação. 
O curso de formação de professores envolveu quatro etapas:

1) Reunião na Secretaria de Educação com a comissão da Feira de Conhecimento do município para verificar o público-alvo e as temáticas que seriam abordadas na formação. Barcelos, Jacobucci e Jacobucci (2010) argumentam que, como qualquer outra atividade de ensino e aprendizagem que envolve criatividade e investigação na busca de soluções para uma situação problematizadora, a realização de uma Feira Científico-cultural requer um pré-projeto, visto que um evento dessa natureza depende de uma série de medidas e providências que devem ser pré-programadas.

2) Escolha das temáticas da formação, cujo título foi "Pesquisa Científica". Os conteúdos escolhidos para serem trabalhados com os professores em formação foram: conceito de pesquisa científica; sua importância; introdução da pesquisa científica na sala de aula; tipos de pesquisa científica; orientações para elaboração do plano de pesquisa; explicações sobre o que é um caderno de campo e como fazer as anotações; orientações para a elaboração do relatório de pesquisa.

3) Elaboração do material para apresentação. Para elaborar o material a ser utilizado para a formação, optou-se por uma busca em livros e artigos com informações condizentes com o objetivo da proposta formativa.

4) Elaboração de um questionário, que continham questões abertas sobre o perfil profissional e de conhecimentos sobre pesquisa científica e as percepções dos professores sobre a formação.

O curso de formação de professores ocorreu na universidade promotora da formação, com duração de quatro horas para os professores do Ensino Fundamental dos anos iniciais no período da manhã, e quatro horas para os professores do Ensino Fundamental dos anos finais no período da tarde.

A formação teve início com a apresentação das professoras que iriam ministrar o curso, e seguiu com o assunto que seria tratado, contando com o auxílio do material de slides pré-elaborados, a partir do qual foi realizada uma exposição dialogada com os participantes. Durante toda a formação buscou-se, além de apresentar a temática, possibilitar abertura aos docentes para que participassem com suas opiniões, a fim de construir um momento mais enriquecedor.

A formação contou com o relato de três alunos da Iniciação Científica Júnior, falando da pesquisa e o impacto dela em suas vidas. Os discentes relataram as te- 
máticas que pesquisam, exemplificando os banners apresentados por eles em eventos científicos e relatando como a pesquisa científica foi modificando seus hábitos de estudo e crescimento, tanto acadêmico, como pessoal.

Para encerrar a formação, foi aplicado um questionário, de questões abertas, com o objetivo de analisar as percepções dos professores sobre a pesquisa científica, suas dificuldades de implementação neste nível de ensino e qual a contribuição da formação realizada. Segundo Gil (2002) o questionário consiste basicamente em traduzir os objetivos da pesquisa de forma bem redigida, não existindo uma norma rígida para sua elaboração.

Os dados obtidos foram avaliados com base na Análise de Conteúdo, como proposta por Bardin (2011). A Análise de Conteúdo é um conjunto de técnicas de análise das comunicações visando obter, por procedimentos sistemáticos e objetivos, a descrição do conteúdo das mensagens que permitam a inferência de conhecimentos relativos às condições de produção/recepção destas mensagens (BARDIN, 2011). Para cada pergunta analisada foi construído um quadro, expressando a categoria, subcategorias primárias, frequências das respostas e percentuais.

\section{Resultados}

\section{Caracterização dos participantes da pesquisa}

A formação contou com 81 professores do Ensino Fundamental do município, onde a média de idade dos professores foi de 39,95 anos, sendo o mínimo 27 anos e o máximo 58 anos. Referente ao tempo que os professores atuam no ensino, a média foi de 14,16 anos, com o mínimo de dois anos e máximo de 30 anos. Tardif e Raymond (2000) mencionam que a experiência profissional é um fator que contribui para a prática pedagógica dos professores, pois ela é crucial na aquisição do sentimento de competência e na implantação das rotinas do trabalho.

Com relação aos cursos de graduação dos professores, atuam em diferentes áreas do conhecimento, oriundos de variados cursos, como se observa na Tabela 1. 
Tabela 1: Graduação dos professores participantes da formação.

\begin{tabular}{l|r|r}
\multicolumn{1}{c|}{ Curso de Graduação } & $\mathrm{N}$ & \% \\
\hline Pedagogia & 26 & 32,2 \\
Letras & 14 & 17,4 \\
Ciências Biológicas & 12 & 14,8 \\
História & 9 & 11,2 \\
Matemática & 6 & 7,4 \\
Química & 3 & 3,7 \\
Educação Física & 2 & 2,4 \\
Geografia & 2 & 2,4 \\
Filosofia & 2 & 2,4 \\
Artes Visuais & 2 & 2,4 \\
Administração & 1 & 1,3 \\
Não respondeu & 2 & 2,4 \\
\hline Total & 81 & 100 \\
\hline Fonte: Organizado pelos autores. & &
\end{tabular}

Referente a área de formação dos professores, observa-se que $32,2 \%(\mathrm{~N}=26)$ tem formação em Pedagogia, atuando nos anos iniciais do Ensino Fundamental. Rosa, Darroz e Minosso (2019) destacam que os anos iniciais são parte importante e significativa na vida escolar, pois nesta fase as crianças estão sedentas por descobrirem coisas novas, são extremamente curiosas e criativas. Para os autores, além de ensinar a ler e a escrever, os professores dos anos iniciais precisam desenvolver e incentivar o pensamento crítico, questionador e observador das crianças, particularmente vinculado e favorecido pela ciência. Outras formações de maior frequência de representação entre os participantes foram em Letras $(17,4 \%$; N=14) e Ciências Biológicas $(14,8 \%, \mathrm{~N}=12)$.

A partir dos dados da Tabela 1 é possível verificar, também, uma frequência menor de participação na formação de professores oriundos das disciplinas da área das Ciências Humanas, como História, Geografia, Filosofia e Artes (N=9, 2, 2, 2, respectivamente). Isso pode ter relação com o fato de que, geralmente, atribui-se à área das Ciências da Natureza uma aproximação maior com as atividades de pesquisa e feiras, a exemplo das feiras de Ciências, realizadas em diversas escolas.

No entanto, cabe ressaltar que as Feiras do Conhecimento (à exemplo da feira mencionada neste estudo) destinam-se à pesquisa científica em todas as áreas e não 
se limitam às Ciências da Natureza. Esta diferenciação precisa, ainda, ser melhor compreendida pelos gestores, professores, alunos e comunidade em geral. Gauterio, Guidotti e Araújo (2017) discutem esta questão, mencionando que as feiras foram voltadas por muito tempo a disciplinas de Ciências da Natureza, mas que com o passar do tempo esta visão se ampliou e estes eventos passaram a ser reconhecidos como espaço de investigação científica para todas as áreas do conhecimento.

\section{Análise das percepções dos professores}

A análise da questão "Qual a importância de trabalhar a pesquisa científica como os alunos do Ensino Fundamental?" se encontra categorizada no Quadro 1:

Quadro 1: Importância de trabalhar a pesquisa científica como os alunos do Ensino Fundamental

\begin{tabular}{|c|c|c|c|}
\hline Categoria & Subcategorias primárias & $\mathrm{N}$ & $\%$ \\
\hline \multirow{17}{*}{$\begin{array}{l}\text { Trabalhar pesquisa } \\
\text { científica com os alunos no } \\
\text { Ensino Fundamental }\end{array}$} & Adquirir novos conhecimentos de forma organizada & 26 & 32,0 \\
\hline & Despertar a curiosidade & 8 & 8,6 \\
\hline & Autonomia & 8 & 8,6 \\
\hline & Gosto pela pesquisa & 7 & 7,5 \\
\hline & Autorregulação & 6 & 6,5 \\
\hline & Organização & 5 & 5,3 \\
\hline & Estimula a leitura & 5 & 5,3 \\
\hline & Pensamento crítico & 5 & 5,3 \\
\hline & Capacidade sócio-cognitiva & 4 & 4,3 \\
\hline & Capacidade de resolver problemas & 4 & 4,3 \\
\hline & Formas mais elaboradas de pensamento & 3 & 3,2 \\
\hline & Preparar para os próximos anos & 3 & 3,2 \\
\hline & Preparar para a vida & 3 & 3,2 \\
\hline & Trabalho em equipe & 2 & 2,2 \\
\hline & Aprendizagem científica & 2 & 2,2 \\
\hline & Criatividade & 1 & 1,1 \\
\hline & Apresentar possibilidades & 1 & 1,1 \\
\hline Total & & 93 & 100 \\
\hline
\end{tabular}

Fonte: Organizado pelos autores

A subcategoria mais expressiva sobre a importância de trabalhar a pesquisa científica com os alunos foi quanto à aquisição de conhecimentos de forma organi- 
zada, expressa com uma frequência de $32 \%(\mathrm{~N}=26)$ dos participantes. Este aspecto demonstra ser importante, pois, embora na contemporaneidade as informações estejam amplamente disponíveis nos meios de comunicação, apenas este acesso não garante a aprendizagem e aquisição crítica de conhecimento. Neste sentido, a partir destas respostas, observa-se que os docentes participantes desta pesquisa têm a clareza da necessidade de conduzir os alunos em uma obtenção de conhecimentos de maneira organizada e crítica. Para Demo (2011) o conceito de pesquisa é fundamental no processo de ensino e aprendizagem, pois desperta a curiosidade, a inquietude, o desejo de descoberta e criação, sobretudo a atitude política emancipatória de construção do sujeito social competente e organizado.

Outros dois aspectos importantes salientados pelos professores e que contribuem para que os alunos possam adquirir habilidades de pesquisa são a curiosidade e a autonomia $(8,6 \% ; \mathrm{N}=8)$. Igualmente significativo, dois outros pontos mencionados foram o gosto pela pesquisa e a autorregulação ( $\mathrm{N}=7$ e 6 , respectivamente). Ovigli, Lourenço e Colombo Junior (2016) comentam que uma reflexão acerca de atividades interdisciplinares e investigação científica é necessária porque confere mais significado aos saberes escolares, dinamizando as atividades dos professores e a interação destes com os estudantes.

Para Chassot (2003) se fará a alfabetização científica quando o ensino da ciência, em qualquer nível, contribuir para a compreensão de procedimentos, conhecimentos e valores que permitam aos alunos tomarem decisões e perceberem as muitas utilidades da ciência, bem como as suas aplicações para melhorar a qualidade de vida, e as suas limitações e consequências negativas de seu desenvolvimento.

A segunda pergunta: "Para você, esta formação contribuiu para um melhor entendimento sobre a pesquisa científica? Comente.”, está categorizada no Quadro 2: 
Formação continuada de professores do Ensino Fundamental: percepções a respeito da pesquisa científica e sua...

Quadro 2: Contribuição da formação para o entendimento da pesquisa científica

\begin{tabular}{|c|c|c|c|c|}
\hline Categoria & $\begin{array}{c}\text { Subcategoria } \\
\text { primária }\end{array}$ & Subcategoria secundária & $\mathrm{N}$ & $\%$ \\
\hline \multirow{12}{*}{$\begin{array}{l}\text { Contribuição da } \\
\text { formação para um } \\
\text { melhor entendimento } \\
\text { sobre pesquisa } \\
\text { científica }\end{array}$} & \multirow{10}{*}{ Sim } & Para relembrar & 17 & 21,0 \\
\hline & & Para esclarecer como realizar uma pesquisa & 11 & 13,6 \\
\hline & & Orientação sobre pesquisa científica & 8 & 9,9 \\
\hline & & Auxiliou, mas é difícil de aplicar & 7 & 8,6 \\
\hline & & Foi esclarecedora & 7 & 8,6 \\
\hline & & Forneceu exemplos práticos & 7 & 8,6 \\
\hline & & Motivação & 5 & 6,2 \\
\hline & & Demonstrou a importância da pesquisa no EF & 2 & 2,4 \\
\hline & & Atualização & 2 & 3,7 \\
\hline & & Sem justificativa & 12 & 14,8 \\
\hline & Pouco & Já trabalhava esses passos com os meus alunos & 1 & 1,3 \\
\hline & Não respondeu & & 1 & 1,3 \\
\hline Total & & & 81 & 100 \\
\hline
\end{tabular}

Fonte: Organizado pelos autores

A partir do Quadro 2, se observa que quase a totalidade de professores participantes da formação avaliaram a mesma como significativa para um melhor entendimento da pesquisa científica. No entanto, as justificativas apresentaram-se bastante diversificadas, ou ausentes $(14,8 \% ; \mathrm{N}=12)$. Entre as mais expressivas, os professores destacaram uma retomada sobre pesquisa científica ( $21 \%$; $\mathrm{N}=17)$, esclarecimentos e orientação sobre como realizar pesquisa $(13,6 \% ; \mathrm{N}=11)$.

Os docentes conhecedores da pesquisa científica possuem maior suporte para a inovação e habilidades na produção de novos conhecimentos, o que os ajuda a desenvolver estas capacidades também em seus alunos, aproximando teoria e prática, além de estarem em constante repensar de suas atividades (SOUZA; CEDRO; MORBECK, 2019).

A categorização da pergunta "Você acredita que pode ter alguma dificuldade de trabalhar a pesquisa científica nas aulas? Justifique.”, é apresentada no Quadro 3: 
Quadro 3: Dificuldades de trabalhar a pesquisa científica nas aulas.

\begin{tabular}{|c|c|c|c|c|}
\hline Categoria & $\begin{array}{l}\text { Subcategoria } \\
\text { primária }\end{array}$ & Subcategoria secundária & $\mathrm{N}$ & $\%$ \\
\hline \multirow{13}{*}{$\begin{array}{l}\text { Dificuldades de } \\
\text { trabalhar pesquisa } \\
\text { cientifica nas aulas }\end{array}$} & \multirow{10}{*}{ Sim } & Limitação dos alunos & 20 & 24,7 \\
\hline & & Tempo & 18 & 22,2 \\
\hline & & Falta de recursos & 13 & 16,0 \\
\hline & & Falta de equipe & 5 & 6,2 \\
\hline & & Dominar os passos da pesquisa & 5 & 6,2 \\
\hline & & Orientar um grande número de alunos & 5 & 6,2 \\
\hline & & Muito elaborado e teórico para o EF & 4 & 4,9 \\
\hline & & Resistência dos professores & 3 & 3,7 \\
\hline & & Sobrecarga de trabalho & 3 & 3,7 \\
\hline & & Necessário trabalhar extraclasse & 2 & 2,5 \\
\hline & \multirow{3}{*}{ Não } & Adaptar-se sempre & 1 & 1,2 \\
\hline & & É possível & 1 & 1,2 \\
\hline & & Boa expectativa & 1 & 1,2 \\
\hline Total & & & 81 & 100 \\
\hline
\end{tabular}

Fonte: Organizado pelos autores.

Com base no Quadro 3 é possível perceber que a maioria dos professores $(96,4 \%$, $\mathrm{N}=78$ ) relatam encontrar dificuldades para trabalhar a pesquisa científica nas aulas; aspectos como a limitação dos alunos, a falta de tempo para desenvolvê-la na escola e a escassez de recursos para esta finalidade foram mencionados. Longui e Schroeder (2012) levantaram as concepções de professores sobre iniciação científica em uma rede municipal de Blumenau/SC, e verificaram que os docentes, embora apresentem noções sobre como realizar pesquisa científica, ainda encontram dificuldades para transpor isso em sua prática, nos contextos em que atuam.

Sasseron (2019) relata que o ensino de ciências e por investigação pode estimular a construção de conhecimentos a partir da busca por informações e criatividade para realizá-la, mas estas características dependem do papel assumido pelo docente. Para Azevedo (2004), o professor deve adotar uma nova postura nesta abordagem, estimulando o questionamento, a argumentação, levando assim a uma proposta mais mediadora entre o que se ensina e o que se aprende, propondo desafios aos alunos, deixando de ser apenas um expositor de conteúdos e promovendo movimentos nas relações entre docentes e discentes, proporcionando experiências significativas.

A categorização da pergunta "Você acredita que essa formação foi válida para você trabalhar a pesquisa científica com os alunos e incentivá-los a participar da Feira do Conhecimento? Justifique.”, encontra-se disponível no Quadro 4: 
Formação continuada de professores do Ensino Fundamental: percepções a respeito da pesquisa científica e sua...

Quadro 4: Validade da formação realizada para trabalhar pesquisa científica com os alunos.

\begin{tabular}{|c|c|c|c|c|}
\hline Categoria & $\begin{array}{l}\text { Subcategoria } \\
\text { primária }\end{array}$ & Subcategoria secundária & $\mathrm{N}$ & $\%$ \\
\hline \multirow{11}{*}{$\begin{array}{l}\text { Validade da } \\
\text { formação realizada } \\
\text { para trabalhar } \\
\text { pesquisa científica } \\
\text { com os alunos }\end{array}$} & \multirow{9}{*}{ Sim } & Práticas e ideias para despertar o interesse dos alunos & 18 & 22,2 \\
\hline & & $\begin{array}{l}\text { Boa orientação para trabalhar com os alunos na Feira } \\
\text { do Conhecimento }\end{array}$ & 11 & 13,6 \\
\hline & & Entendimento/preparação & 11 & 13,6 \\
\hline & & Exige adaptações & 5 & 6,2 \\
\hline & & Porém os passos são complexos para o EF & 5 & 6,2 \\
\hline & & Incentivou & 2 & 2,5 \\
\hline & & Didático & 2 & 2,5 \\
\hline & & A IC tem que fazer parte do currículo & 1 & 1,3 \\
\hline & & Sem justificativa & 24 & 29,6 \\
\hline & Pouco & Sem justificativa & 1 & 1,3 \\
\hline & Não & Creio que oficinas práticas seriam mais produtivas & 1 & 1,3 \\
\hline Total & & & 81 & 100 \\
\hline
\end{tabular}

Fonte: Organizado pelos autores.

Sobre a formação como válida para trabalhar pesquisa científica com os alunos e incentivá-los a participar da Feira do Conhecimento (Quadro 4) a maioria dos participantes salientaram que ajudou, de forma mais expressiva, quanto a ideias de como despertar o interesse dos alunos $(22,2 \%, \mathrm{~N}=18)$ e orientação para trabalhar com eles na Feira do Conhecimento (13,6\%, N=11).

Um dos temas mais polêmicos na discussão sobre formação de professores é o quanto se precisa procurar uma ciência da escola (o saber escolar, que envolve um processo de reelaboração de saberes de outros contextos sociais visando o atendimento das finalidades sociais da escolarização), que é significativamente diferente daquela ciência da universidade (o saber acadêmico) (LOPES, 1999; CHASSOT, 2003). É usual defender, principalmente pela imensa dificuldade de se fazer transposição de conteúdos do Ensino Superior para o Ensino Médio e Ensino Fundamental, que o conhecimento científico é universal (CHASSOT, 2003).

Bogner, Boudalis e Sotiriou (2014) relatam que não existe uma descrição teórica que possa ser encaminhada aos professores para garantir a educação científica; o docente necessita ter formação adequada para compreender que as variáveis no processo de investigação dos alunos serão diversas, e saber conduzi-las para que o aluno construa suas observações é fundamental no ensino. Aos docentes é necessário esclarecer que não serão eles quem irão liderar os processos de investigação, mas sim os próprios alunos. Essa postura docente muitas vezes traz insegurança e incertezas, tendo em vista que estes profissionais carregam consigo a experiência 
de um processo de educação onde seus professores eram o centro do ensino, mas, modificar essa concepção na formação inicial de professores é necessário, considerando as tendências metodológicas que visam um aluno crítico participativo no seu processo de ensino (PERRENOUD, 2002).

Perante o exposto, a pesquisa relacionada à investigação científica é um desafio para os docentes do século XXI, especialmente porque se percebe a carência na formação inicial, a falta de incentivo para uma formação continuada, a não presença efetiva de políticas públicas que incentive essa contínua busca pela aprendizagem, entre outras. A problemática é grande, as discussões são muitas, mas, apesar disso, há uma lenta movimentação estimulada pela obrigatoriedade de implementação da BNCC, a qual traz como premissa o letramento científico já desde a Educação Infantil, o que é extremamente relevante para que os alunos possam se familiarizar com a pesquisa científica desde os primeiros anos de escolaridade.

\section{Considerações finais}

Há muitos relatos de que as formações de professores podem auxiliar no processo de ensino e aprendizagem, bem como fornecer suporte para os professores. Portanto, é importante investigar o quanto os docentes estão preparados para trabalhar com a pesquisa científica e como pretendem aplicá-la na sala de aula.

Esta pesquisa teve por objetivo analisar as percepções de professores do Ensino Fundamental sobre pesquisa científica, suas dificuldades de implementação nesse nível de ensino e qual a contribuição da formação realizada para a orientação da pesquisa científica para a Feira do Conhecimento.

Os resultados revelam que os professores participantes da formação realizada expressaram, em sua maioria, que consideram importante trabalhar a pesquisa científica com os alunos do Ensino Fundamental, atribuindo a este posicionamento justificativas como a aquisição de conhecimentos de forma mais organizada, despertar a curiosidade e a autonomia dos alunos.

Apontaram como as dificuldades mais impactantes na implementação da pesquisa científica no Ensino Fundamental aspectos como as limitações dos alunos, a falta de tempo para desenvolver pesquisa científica na escola e a falta de recursos para esta finalidade. Estes dados demonstram que existem desafios na implementação da pesquisa científica no Ensino Fundamental, segundo os professores participantes 
da formação; estes desafios, por vezes, geram desestímulo aos docentes na tentativa de inserir a pesquisa científica neste nível de ensino.

Referente à contribuição da formação para melhor entender a pesquisa cientifica, os docentes mencionaram que foi bastante válida, especialmente por melhorar o entendimento da pesquisa científica, relembrar aspectos de como desenvolvê-la. Quanto à aplicação destes conhecimentos com os alunos, os professores apontaram que a formação contribuiu por proporcionar práticas e ideias que podem despertar interesse dos discentes, garantiu um suporte e orientação para a aplicação da pesquisa científica em sala de aula e para auxiliar na construção de trabalhos para a Feira do Conhecimento.

A Feira do Conhecimento, portanto, apresenta-se como uma das possibilidades de introduzir a pesquisa cientifica na educação básica, incentivando essa prática, que pode, posteriormente, aprofundar-se, de modo a ocorrer de forma mais ampla e constante.

Esses resultados têm implicações importantes para pesquisadores e educadores que desejam investigar e/ou implementar a pesquisa científica desde os primeiros anos do Ensino Fundamental, tendo como base a sua importância, além das indicações da BNCC para sua realização. Assim, recomenda-se que os colegas estudiosos considerem as informações encontradas neste estudo sobre a formação docente para a pesquisa científica e possam levantar mais dados sobre estes aspectos investigados com outros docentes, nos mais variados contextos.

\section{Continuing Education of Elementary School Teachers: Working with Scientific Research to Assist in the Knowledge Fair}

\section{Abstract}

The study goal to analyze teachers' perceptions about scientific research, such as difficulties of implementation at this level and the contribution of the training provided for the orientation of scientific research for the Knowledge Fair. This is a case study of qualitative nature, involving 81 teachers from the initial and final years of elementary school from 24 schools in a municipal network in Porto Alegre the metropolitan region, RS. A questionnaire was applied about the professional profile, knowledge about scientific research and teachers' perceptions about training, which was analyzed based on Content Analysis. The results revealed that teachers consider it important to work on scientific research with students and pointed out aspects such as the lack of time to develop it at school and the lack of resources for this purpose as the most impacting difficulties in implementing scientific research in elementary school. They attributed the training as valid for improving understanding on the subject, ensuring support and guidance for the application of scientific research in the classroom and assisting in the construction of works for the Knowledge Fair.

Keywords: Scientific research. Teacher training. Elementary School. Knowledge Fair. 


\section{Apoio recebido}

O presente trabalho foi realizado com apoio da Coordenação de Aperfeiçoamento de Pessoal de Nível Superior- Brasil (CAPES) - Código de Financiamento 001.

\section{Referências}

AZEVEDO, M. C. P. S. Ensino por investigação: problematizando as atividades em sala de aula. In: CARVALHO, A. M. P. (Org.). Ensino de ciências: unindo a pesquisa e a prática. São Paulo: Pioneira Thomson Learning, 2004. p.19-33.

BARCELOS, N. N. S.; JACOBUCCI, G. B.; JACOBUCCI, D. F. C. Quando o cotidiano pede espaço na escola, o projeto da feira de ciências "Vida em Sociedade" se concretiza. Ciência \& Educação, v. 16, n. 1 , p. 215-233, 2010.

BARDIN, L. Análise de Conteúdo. São Paulo: Edições 70, 2011.

BEDIN, E.; DEL PINO, J. C. Dicumba: uma proposta metodológica de ensino a partir da pesquisa em sala de aula. Ensaio: Pesquisa em Educação em Ciências, v. 21, p. 1-22, 2019.

BERNARDES, A. O.; PEIXOTO, E. S. A importância da iniciação científica no ensino médio: uma discussão a partir do trabalho realizado no ensino de Física no Colégio Estadual Canadá de Nova Friburgo-RJ. In: Congresso Nacional de Educação, 5, Olinda/PE. Anais. 2018.

BIANCHETTI, L.; DE OLIVEIRA, A.; DA SILVA, E. L.; TURNES, L. A iniciação à pesquisa no Brasil: políticas de formação de jovens pesquisadores. Educação, v. 37, p. 569-584, 2012.

BOGNER, F; BOUDALIS, A. K.; SOTIRIOU, S. Inquiry based science education, do projeto inspiring science: large scale experimentation scenarios to mainstream elearning. Science: Mathematics and Technology in Primary and Secondary Schools, v.1, p. 1-70, 2014.

BRASIL. Conselho Nacional de Educação/Conselho Pleno. Diretrizes Curriculares Nacionais para a Formação de Professores da Educação Básica, em nível superior, curso de licenciatura, de graduação Plena. Brasília, Resolução CNE/CP 1, de 18 de fevereiro de 2002. Disponível em: http://portal.mec.gov.br/cne/arquivos/pdf/CP012002.pdf

BRASIL. Base Nacional Comum Curricular. Brasília: MEC, 2019. Disponível em: http:// basenacionalcomum.mec.gov.br/wp-content/uploads/2018/03/4-apresentacao-complementar-atividades-extra.pdf.

CHASSOT, A. Alfabetização científica: questões e desafios para a educação. Ijuí: Unijuí, 1. ed., 2000.

CHASSOT, A. Alfabetização científica: uma possibilidade para a inclusão social. Revista Brasileira de Educação, n. 22, p. 89-100, 2003.

CRISOSTIMO, A. L.; SANTOS, S. A.; SILVA, V. S.; FERRARI, S. C. Contribuições do programa de desenvolvimento educacional (PDE/UNICENTO-PR) na formação de professores de ciências e biologia. e-Mosaicos- Revista Multidisciplinar de Ensino, Pesquisa, Extensão e Cultura, v. 7, n. 14, p. 89-103, 2018.

DEMO, P. Pesquisa: princípio científico e educativo. 14. ed. São Paulo: Cortez, 2011. 
FARIAS, L. N. Feiras de Ciências como oportunidades de (re)construção do conhecimento pela pesquisa. 2006. 89f. Dissertação (Mestrado em Educação em Ciências e Matemáticas) - Núcleo Pedagógico de Apoio ao Desenvolvimento Científico, Universidade Federal do Pará, Belém, 2006.

FAVA-DE-MORAES, F.; FAVA, M. A iniciação científica muitas vantagens e poucos riscos. São Paulo em Perspectiva, v. 14, p. 73-77, 2000.

GALIAZZI, M. do C.; MORAES, R. Educação pela pesquisa como modo, tempo e espaço de qualificação da formação de professores de ciências. Ciência \& Educação (Bauru), v. 8, n. 2, p. 237-252, 2002.

GAUTERIO, P. C.; GUIDOTTI, L. S.; ARAÚJO. R. R. Feira de Ciências: Espaço de interação e investigação na formação continuada de professores. In: Encontro Nacional de Pesquisa em Educação em Ciências, 11, Universidade Federal de Santa Catarina, Florianópolis. Anais, 2017.

GIL, A. C. Como elaborar projetos de pesquisa. 4. ed. São Paulo: Atlas, 2002.

LONGUI, A.; SCHROEDER, E. Clubes de ciências: o que pensam os professores coordenadores sobre ciência, natureza da ciência e iniciação científica numa rede municipal de ensino. Revista Electrónica de Enseñanza de las Ciencias, v. 11, n. 3, p. 547-564, 2012.

LOPES, A. R. C. Conhecimento escolar: ciência e cotidiano. Rio de Janeiro: Editora da UERJ, 1999.

MANCUSO, R. Feiras de ciências: produção estudantil, avaliação, consequências. Contexto Educativo - Revista digital de Educación y Nuevas Tecnologias, n. 6, abr. 2000.

MATTOS, E. B. V.; BONA, A. S.; BASSO, M. V. A.; FAGUNDES, L. C. Iniciação Científica e a Aprendizagem de Matemática na Educação Básica. Revista Iberoamericana de Educación en Tecnología y Tecnología en Educación, n. 18, p. 41-50, 2016.

OVIGLI, D. F. B. Iniciação Científica na Educação Básica: uma atividade mais do que necessária. Revista Brasileira de Iniciação Científica, v. 1, n. 1, p. 1-13, 2014.

OVIGLI, D. F. B.; LOURENÇO, A. B.; COLOMBO JUNIOR, P. D. Formação docente para Educação do Campo: as habilitações em Ciências da Natureza e Matemática. Revista Internacional de Formação de Professores, v. 1, n. 3, p. 80-92, 2016.

OVIGLI, D. F. B.; COLOMBO JUNIOR, P. D.; GALANTE, L. A. R. Parceria escola-universidade: as feiras de conhecimentos como meio de divulgação científica. Ciências em Foco, v. 12, n. 1, p. 186-195, 2019.

PERRENOUD, P. A prática reflexiva no ofício de professor: Profissionalização e Razão Pedagógica. Porto Alegre: Artmed Editora, 2002.

ROCHA, S. M. L. Projeto de iniciação científica discente: relato de projeto de trabalho desenvolvido na educação infantil da ESEBA. Olhares e Trilhas, n. 11, p. 77-83, 2010.

ROSA, C. T. W.; DARROZ, L. M.; MINOSSO, F. B. Alfabetização científica e ensino de ciências nos anos iniciais: concepções e ações dos professores. Revista Brasileira de Ensino de Ciência e Tecnologia, v. 12, n. 1, 2019.

SASSERON, L. H. Sobre ensinar ciências, investigação e nosso papel na sociedade. Ciência \& Educação, v. 25, n. 3, 2019. 
SCHWARTZMAN, S. Um espaço para a ciência: a formação da comunidade científica do Brasil. 4. ed. Campinas: Editora da Unicamp, 2015.

SILVA, E. C.; MOURA, J. F. Análise das feiras científicas das escolas da educação básica de Imperatriz/MA divulgadas pelo jornal ‘o progresso': temáticas emergentes. InterEspaço, v. 5, n. 16, p. 01-24, 2019.

SILVEIRA, J. C.; CASSIANI, S.; LINSINGEN, I. V. Writing and authorship in scientific initiation text in elementary education: is it possible to have another relationship with knowledge? Ciência \& educação. 2018, v. 24, n. 1, p. 9-25, 2018.

SOUZA, L. O.; CEDRO, P. E. P.; MORBECK, L. L. B. Relevância da Pesquisa Científica para a Formação de Professores de Biologia e a Prática Docente. Id on Line Revista Multidisciplinar e de Psicologia, v. 13, n. 45, p. 318-330, 2019.

TARDIF, M.; RAYMOND, D. Saberes, tempo e aprendizagem do trabalho no magistério. Educação \& Sociedade, v. 21, n. 73, p. 209-244, 2000.

THOMÉ, N. Relato de um trabalho experimental de iniciação científica júnior no município de curitibanos (SC) para a história da educação. In: Congresso Nacional de Educação, 11, Pontifícia Universidade Católica do Paraná, Curitiba, Anais, 2013.

YIN, R. K. Estudo de caso: planejamento e métodos. 5. ed. Porto Alegre: Bookman, 2015.

YIN, R. K. Pesquisa qualitativa do início ao fim. Tradução: Daniel Bueno. Porto Alegre: Penso, 2016.

ZOMPERO, A. F.; SOUZA, C. H. B.; GARBIM, T. H. S.; BARICHELLO, D. Conhecimentos de alunos de Iniciação Científica Júnior sobre procedimentos em Ciência. REENCIMA, v. 10, n. 1, p. 48-64, 2019. 